\title{
OIKOS
}

\section{A Continent-Scale Test of Multiple Hypotheses on the Abundances of Neotropical Birds}

\begin{tabular}{|c|c|}
\hline Journal: & Oikos \\
\hline Manuscript ID & OIK-05625.R2 \\
\hline Wiley - Manuscript type: & Research \\
\hline Keywords: & energy limitation, species interaction, density compensation \\
\hline Abstract: & $\begin{array}{l}\text { Explaining variation in the abundance of species remains a challenge in } \\
\text { ecology. We sought to explain variation in abundance of Neotropical forest } \\
\text { birds using a dataset of population densities of } 596 \text { species. We tested a } \\
\text { priori hypotheses for the roles of species traits, environmental factors, and } \\
\text { species interactions. Specifically, we focused on four factors: } 1 \text { ) body mass } \\
\text { (trait); 2) habitat type (environmental factor), 3) net primary productivity } \\
\text { (NPP; environmental factor); and 4) species richness of competitors } \\
\text { (species interaction). Body size explained much variation in density, } \\
\text { although only when analyzed at higher taxonomic levels. Habitat type was } \\
\text { a strong predictor of density. The relationship between density and } \\
\text { productivity was weak. Densities were related negatively to the species } \\
\text { richness of heterospecifics, however - this trend was particularly strong } \\
\text { within closely related groups. Our results show that the influence of } \\
\text { energetic factors such as body size and productivity depends on phylogeny, } \\
\text { and they act through indirect relations with other variables; alternative } \\
\text { ecological factors such as habitat structure and species interactions play a } \\
\text { more direct and stronger role in determining abundance than previously } \\
\text { thought. }\end{array}$ \\
\hline \multicolumn{2}{|c|}{$\begin{array}{l}\text { Note: The following files were submitted by the author for peer review, but cannot be converted to } \\
\text { PDF. You must view these files (e.g. movies) online. }\end{array}$} \\
\hline DataA1.csv & \\
\hline
\end{tabular}


1 A Continent-Scale Test of Multiple Hypotheses on the Abundances of Neotropical Birds

2 David W. Kikuchi ${ }^{1, \dagger}$, Gustavo H. Kattan ${ }^{2,}$, Kimberly C. Navarro Vélez ${ }^{3}$

3

4

${ }^{1}$ Department of Ecology and Evolutionary Biology, University of Arizona, Tucson, AZ, USA

${ }^{2}$ Departamento de Ciencias Naturales y Matemáticas, Pontificia Universidad Javeriana Cali, Cali, Colombia

$7 \quad{ }^{3}$ Departamento de Biología, Universidad del Valle, Cali, Colombia

${ }^{\dagger}$ CORRESPONDING AUTHOR: e-mail: dkikuchi@email.arizona.edu

11 Ecology and Evolutionary Biology

12 University of Arizona

13 P.O. Box 210088

14 Tucson, AZ 85721

15 PHONE: +1-520-626-5565

16 FAX: +1-520-621-9190

17 ORCID: $\underline{0000-0002-7379-2788}$

‡e-mail: gustavokattan@gmail.com

SHORT TITLE: Abundance of birds

22 KEY WORDS: Bird abundance, energy limitation, species interaction, Andes, Amazon, density

23 compensation

24

Number of words in main text: 5324 
Neotropical Bird Abundance

\section{Abstract}

29 Explaining variation in the abundance of species remains a challenge in ecology. We sought to

30 explain variation in abundance of Neotropical forest birds using a dataset of population densities

31 of 596 species. We tested a priori hypotheses for the roles of species traits, environmental

32 factors, and species interactions. Specifically, we focused on four factors: 1) body mass (trait); 2)

33 habitat type (environmental factor), 3) net primary productivity (NPP; environmental factor); and

34 4) species richness of competitors (species interaction). Body size explained much variation in

35 density, although only when analyzed at higher taxonomic levels. Habitat type was a strong

36 predictor of density. The relationship between density and productivity was weak. Densities were

37 related negatively to the species richness of heterospecifics, however - this trend was particularly

38 strong within closely related groups. Our results show that the influence of energetic factors such

39 as body size and productivity depends on phylogeny, and they act through indirect relations with

40 other variables; alternative ecological factors such as habitat structure and species interactions

41 play a more direct and stronger role in determining abundance than previously thought. 
Neotropical Bird Abundance

\section{Introduction}

43 A fundamental question in ecology is how the abundance of species is governed (McGill 2008,

44 Storch et al. 2018), which is central to numerous ecological and evolutionary processes (e.g.

45 Gotelli 1995, Charlesworth 2009). Many factors may influence abundance, including

46 environmental variables (Damuth 1981, Srivastava and Lawton 1998, Kaspari et al. 2000, Brown

47 et al. 2004), species traits (Rosenzweig and Lomolino 1997, Murray et al. 2002, McGill et al.

48 2006, Umaña et al. 2015), and interactions with other species (MacArthur et al. 1972, Hudson et

49 al. 1992, Robertson 1996, Berger and Gese 2007). Despite much investigation, no single factor

50 appears sufficient to explain variation in species abundance (no. individuals/species; Murray et

51 al. 2002, Hurlbert 2004, McGill 2008). Instead, we must examine trends across environmental

52 gradients (McGill et al. 2006), taking into account the separate contribution of abiotic and biotic

53 factors (Warton et al. 2015), while at the same time controlling for correlations between

54 predictor variables (Dormann et al. 2013).

55 Some elements that are hypothesized to be most important for controlling abundance are

56 energy, species interactions, and spatial variation. These broad categories are often broken down

57 into more specific factors. For example, the influence of energy can be broken down into its

58 availability, i.e. productivity, or its use, with limitations imposed by metabolic rates (Brown et al.

59 2004). Below, we describe mechanisms by which some of these factors are hypothesized to

60 function, and connect them with particular predictions. We considered four more specific factors

61 for explaining variation in abundance, and tailored our reasoning to build predictions about how

62 they would influence the population densities of Neotropical forest birds. Bird populations in the

63 Neotropics are poorly studied in comparison with Nearctic ones or those of large mammals. This 
64 makes them an ideal study group to broaden our understanding of general principles that govern

65 variation in animal populations.

66 The first factor that we selected was body size, which is one of the traits most commonly

67 used to model abundance (McGill et al. 2006), and is often found to have explanatory power

68 (White et al. 2007). This relationship is predicted to occur if population sizes scale according to

69 the energy requirements of individuals (Brown 1995, Brown et al. 2004). Formalized as the

70 energetic equivalence rule, the number of animals that can be supported by a given amount of

71 energy is determined by $\mathrm{N} \propto \mathrm{M}^{-3 / 4}$, where $\mathrm{N}$ is the number of individuals of a species, $\mathrm{M}$ is their

72 average body mass, and the value of the exponent describes the relationship between body mass

73 and metabolic rate (Damuth 1981). This predicts that local abundance will decrease with body

74 size. Empirically, the relationship between body size and abundance in bird species is tenuous

75 (Brown and Maurer 1987, Russo et al. 2003); however, greater success has been had in

76 connecting body size to bird abundance at higher taxonomic levels (McGill 2008). Based on

77 these previous results, we hypothesized that body size would best explain variation in species

78 abundance in the Neotropics at higher taxonomic levels (Hurlbert and White 2007, McGill

79 2008).

80 A second factor predicted to govern abundance is the productivity of a locality (Srivastava

81 and Lawton 1998, Kaspari et al. 2000, Hurlbert 2004, Storch et al. 2018). The relationship

82 between productivity and the number of individuals in a community is unresolved (reviewed in

83 Storch et al. 2018). At the very least, however, most theoretical frameworks agree that

84 productivity can place an upper bound on abundance. This could produce a positive correlation

85 between productivity and abundance across localities. We then asked on what scale it makes

86 sense to seek such a correlation. Much variation in species abundance will result from changes in 
Neotropical Bird Abundance

87 habitat type, as some species will be adapted to high-productivity habitats (e.g. rainforest) and

88 others to low-productivity habitats (e.g. dry forest). Therefore, hypothesizing that energy

89 availability regulates species abundance makes most sense for comparisons within habitat types.

90 We call this the productivity hypothesis, which predicts a positive correlation between

91 productivity and species abundance, once the correlation between productivity and habitat has

92 been taken into account.

93 The role of competition in determining macroecological patterns is contentious (Connor and

94 Simberloff 1979, Diamond and Gilpin 1982, Harmon and Harrison 2015, Rabosky and Hurlbert

95 2015). Indeed, null model analyses of species co-occurrence and abundance matrices suggest that

96 certain species may be excluded by direct competitors (Gotelli and McCabe 2002, Ulrich and

97 Gotelli 2010). Whether or not diffuse competition between many species influences abundance

98 across communities at a continental scale is unknown. When more species compete for

99 resources, they may force one another to utilize narrower niches than in the absence of

100 competition (Hutchinson 1957). Conversely, when they experience competitive release, such as

101 after colonizing an island, populations may undergo what has been called density compensation

102 (Crowell 1962, MacArthur et al. 1972, Nilsson 1977, Wright 1980). Fewer competing species

103 could lead to higher population densities if decreased competition allows residents to exploit a

104 wider range of available resources. We call this process the interspecific competitors hypothesis

105 (also called the "Density Compensation Hypothesis"; Ferenc et al. 2016). Above, in the

106 productivity hypothesis, we explain the necessity of controlling for habitat type before

107 examining the effects of productivity on abundance. Therefore, the interspecific competitors

108 hypothesis must also take this into account: its critical prediction is that, after controlling for 
109 variation in productivity within habitat types, birds living in areas with lower species richness

110 will have higher population densities.

111 Finally, habitat type itself may affect abundance. Different habitat structures can partition

112 available energy into more or fewer niches (MacArthur 1957, Willson 1974), affecting which

113 species can live there and their population abundances. If habitats make resources available to

114 consumers in different ways, then species abundance may best be predicted by variation in

115 habitat rather than directly through productivity. We do not have strong a priori hypotheses

116 about how habitat should affect abundance, except that some functional guilds may have higher

117 densities in montane forest than in lowland rainforest (Kattan and Beltran 2002, Ding et al. 2005,

118 Kikuchi 2009, Ferenc et al. 2016).

119 Here, we build models using regression methods to control for correlations between predictor

120 variables. We use them to examine the relative importance of energy, species traits, and species

121 interactions in governing the local abundance of species across a biogeographic region.

\section{Methods}

\section{The Dataset}

125 Many of the Neotropical studies measuring bird abundances were known to us at the outset of

126 this project. Searching through them, and works citing them, provided the backbone of our

127 database. We supplemented our knowledge by searching Google Scholar, JSTOR, and Wiley

128 using the terms "bird density" combined with the names of Neotropical countries and zones in

129 English, Spanish, and Portuguese, as the local abundance of bird species is generally reported as

130 a population density estimate. We read the Introduction and Methods sections of each paper to

131 see if it met our criteria for estimating population density accurately. All papers we included 


\section{Neotropical Bird Abundance}

132 used one or more of three methods to estimate population densities: spot mapping, point counts,

133 and transect counts. All of the studies that used point counts and some studies that used transect

134 counts also used the software Distance to correct for the probability of detecting the animals as a

135 function of perpendicular distance away from the transect (Buckland et al. 2015).

136 For each species in each study, we extracted population density estimates and converted them

137 into individuals $\mathrm{km}^{-2}$. In all analyses reported below, when studies reported multiple estimates

138 for the same species at the same site, we used the median value of those estimates. When

139 different densities were reported for a species within sub-areas of a study site, we registered them

140 as separate observations. For all population density measurements except for one, these sub-areas

141 were far enough apart to register in separate $10 \mathrm{~km}$-resolution grid cells, giving them unique

142 values for the ecological variables we included in the analysis (below); most of the taxa in

143 studies using sub-areas were from the families Cracidae, Strigidae, and Psittacidae. In addition,

144 we recorded the following information for each entry: species taxonomic affiliation (from

145 Cornell's Neotropical Birds Online; Schulenberg 2016), mean body mass (from Handbook of

146 Birds of the World [del Hoyo et al. 2016] and Cornell's Neotropical Birds), its migratory status

147 in the Neotropics, whether it is primarily terrestrial or aquatic, the habitat in which it was

148 documented (Amazonian forest, Atlantic forest, cerrado, chaco, coniferous forest, dry forest,

149 non-Amazonian humid forest, mangrove, mountain forest, open area, paramo, riparian forest, salt

150 marsh, shrubland, tree plantation), whether or not populations were in a continuous tract of forest

151 or a fragmented one, the protection status of the study area, the method of census used, the date

152 of the observation, and the latitude \& longitude of the locality.

153 To clean our dataset, we first excluded aquatic and riparian taxa, because their populations

154 are difficult to census and the energy available in aquatic ecosystems was not addressed by our 
Neotropical Bird Abundance

155 metric of Net Primary Productivity (NPP). Second, we excluded fragmented habitats because we

156 wished to examine ecological processes unaffected by anthropogenic confounding factors such

157 as edge effects (Murcia 1995). Third, we decided to focus on forest habitats because

158 relationships between productivity and abundance are expected to be monotonic within forests;

159 the relationship may reverse in grasslands (Hurlbert 2004). Fourth, we excluded migrants. Fifth,

160 we excluded taxa considered incertae sedis because we were not able to account for the

161 influence of their taxonomic affiliation on population density. In the final dataset that we used

162 for analysis, we retained 1331 records from 47 studies (see Figure 1 for locations and relative

163 number of species measured at each study site). This included 596 species from 310 genera in 54

164 families spread among 21 orders. This dataset is described in Supplementary material Appendix

165 A, Table A1. Associated references are provided in Supplementary material Appendix A,

166 Metadata A1, and visualizations of the dataset are given in Figure 2.

167 In our final dataset, we tested whether different survey methods produced consistent density

168 estimates. Another study has shown that they do so for cracids (Kattan et al. 2016), but cracids

169 are relatively large and easy to survey. Although our dataset is not designed to cross-validate

170 different methods, we wished to obtain some sense of their comparability. To see if densities

171 differed among sampling methods, we used a linear mixed model explaining $\log ($ density) with a

172 fixed effect "method," which had three levels: spot mapping, studies that used the software

173 Distance to correct their estimates, and uncorrected transect counts. We included site as a

174 random intercept because records were unevenly distributed among sites.

175 To provide a measure of energy availability, we used a geographical information systems

176 (GIS) layer for NPP at $1 \mathrm{~km}$ resolution (Zhao et al. 2005). The layer uses the MOD17 algorithm

177 to estimate NPP averaged across the years 2000-2013 in each cell. We did not have NPP data 


\section{Neotropical Bird Abundance}

178 from outside this time window, yet some of the measurements of population density were

179 recorded outside of it. They are from protected areas, however, so we made the assumption that

180 the mean NPP values across 2000-2013 would be an adequate approximation of their NPP at the

181 time of observation.

182 For testing the interspecific competitors hypothesis, we required a measure of species

183 richness. We used a $10 \mathrm{~km}$ resolution layer that represents regional species richness at a

184 landscape scale $\left(100 \mathrm{~km}^{2}\right)$, calculated as the number of overlapping species ranges in each cell

185 (obtained from Birdlife International; Jenkins et al. 2013, Pimm et al. 2014). Ideally, we would

186 have used alpha diversity at each study locality, because competitive interactions such as

187 exploitation, interference, and territoriality take place at a local scale (Kaspari et al. 2000,

188 Jankowski et al. 2012). Complete data on local species richness were not available for many of

189 the study sites in our dataset; however, local species richness is a subset of regional species

190 richness, and the two numbers are highly correlated, although the correlation is moderated by

191 NPP to some degree (White and Hurlbert 2010). We only used the regional richness layer after

192 we controlled for NPP (below), and therefore consider it an adequate proxy for local richness.

193 Furthermore, layers describing the species richness of the clades Psittaciformes, Trochilidae,

194 other non-Passeriformes, Tyranni, and Passeri are provided, which we used to test the

195 interspecific competitors hypothesis within these groups.

196 All of our study areas were on the same scale as our raster files or less. We used the latitude

197 and longitude coordinates provided in each study or georeferenced them based on their

198 descriptions to extract values of NPP and species richness from our GIS layers. For this we used

199 the "extract" function from the package "raster" in R 3.4.4, having obtained the appropriate 
Neotropical Bird Abundance

200 raster files associated with the studies that generated the data (Zhao et al. 2005, Jenkins et al.

$2012013)$.

202

203 Testing mechanisms affecting population density

204 We tested four hypotheses for how the population densities of Neotropical birds are governed.

205 Before analysis, we scaled and centered all of our continuous predictor variables so that they had

206 mean $=0$ and standard deviation $=1$. The exception to this procedure was $\log ($ body mass $)$

207 (hereafter simply body mass), which was only used in initial regressions. The first hypothesis

208 that we tested was that population density should decrease with body mass. Species-level

209 regressions of body mass typically provide a poor fit to avian population densities (Brown and

210 Maurer 1987; McGill 2008). This may be because body mass is a conserved trait that varies

211 more at the level of family and order among birds (Hurlbert and White 2007; McGill 2008),

212 while other traits (presumably also important for governing abundance) vary at lower taxonomic

213 levels. To verify these trends among Neotropical birds, we performed the following analyses: 1)

214 an ordinary least-squares (OLS) regression of the population densities of each species at each site

215 against body mass on a logarithmic scale; 2) a linear mixed model fit with maximum likelihood

216 of $\log ($ density) with no fixed effects, and order/family/genus as random effects; 3) a linear mixed

217 model of $\log$ (mass) regressed without fixed effects, but order/family/genus as random effects;

218 and 4) a log-linear model of the geometric mean densities for each family against the geometric

219 mean body masses for each family (McGill 2008). The first model reveals the inadequacy of

220 species-level analysis. The next two models illustrate that density is explained better at higher

221 taxonomic levels, and that this is strongly related to how variance in body mass varies at those 
Neotropical Bird Abundance

222 levels. The final model examines the relationship between density and body mass at the

223 taxonomic level where it is most appropriate - where most of the variation occurs.

224 The second hypothesis we tested was the habitat hypothesis. We used a linear mixed model

225 of $\log$ (density) against habitat type, with order/family/genus as random effects to control for

226 effects of body size (see Results). This also controls for other phylogenetically conserved traits,

227 potentially including but not limited to trophic level, territorial behavior, nest site preferences,

228 mating system, and life history.

229 The third hypothesis focuses on productivity and predicts that population density increases

230 with NPP, after the correlation between NPP and habitat has been taken into account. We chose

231 sequential regression to control for the correlation between these variables because it creates

232 orthogonal predictor variables while preserving interpretability (Graham 2003, Dormann et al.

233 2013). This method is distinct from regression of residuals, which is not recommended

234 (Freckleton 2002). In sequential regression, one predictor is regressed against another predictor

235 and the residuals of this regression are used as a new predictor. Thus, the new predictor has the

236 desirable property of being orthogonal to the other predictor variable. Therefore, it may be

237 somewhat conservative in estimating the effects of the second variable that is regressed upon the

238 first. We regressed NPP upon habitat type, then used residuals(NPP habitat type) as a new

239 predictor variable. Habitat type and this new predictor variable were fixed effects in a linear

240 mixed effects model of $\log$ (density) with order/family/genus as random effects. The new

241 predictor can only be interpreted as having an effect after its correlation with the other predictor

242 has been taken into account. In our model testing the productivity hypothesis, one finds the effect

243 of NPP on $\log ($ density), independent of its contribution already made through its correlation with

244 habitat type. 
Neotropical Bird Abundance

245

246

247

248

249

250

251

252

253

254

255

256

257

Testing the fourth hypothesis, the interspecific competitors hypothesis, which predicts that population density decreases with species richness, required the creation of a second variable by way of an additional sequential regression. We regressed species richness against habitat type + residuals(NPP $\sim$ habitat type) to create a third predictor variable, and added this to a linear mixed model of $\log ($ density) with the two variables it was regressed against, with order/family/genus as random intercepts. The R pseudocode for the model is $\log ($ density $) \sim$ habitat type + resid(NPP habitat type $)+\operatorname{resid}($ species richness $\sim \operatorname{resid}(\mathrm{NPP} \sim$ habitat type $))+(1$ lorder/family/genus $)$. The effect of species richness is interpreted as independent, but only after its contribution to $\log$ (density) through its correlations with NPP and habitat type have been taken into account.

The richness of all species is an imperfect proxy for the number of competing species. Not all species compete with one another to an equal degree. Furthermore some may participate in other interactions such as predation or mutualism. Generally, it is assumed that the more closely related species are, the more strongly they compete (Losos 2008). Consequently, the test we performed above using the richness of all species is conservative with respect to our hypothesis, because distantly-related species should contribute noise to the signal. However, it is also possible that any result we observe from that test will be driven by another, unmeasured confounding variable that is 1) uncorrelated with habitat or productivity, and 2) drives underlying patterns of species richness and abundance. Therefore, we tested the additional prediction that species within closely related groups should have a stronger effect on each other's densities, compared to the effect that species within more distantly related groups have on each other's densities.

We used linear mixed models to test the relationship between $\log ($ density) and species richness within the follwing clades: non-Passeriformes (excluding Psittaciformes and 
Neotropical Bird Abundance

268 Trochilidae), Psittaciformes, Trochilidae, Tyranni, and Passeri. We used the sequential

269 regression framework described above, but instead of using the richness of all species, we

270 created new predictors using the richness of each group. Assuming that more closely related

271 species compete more strongly, if the interspecific competitors hypothesis is supported, we

272 should see a stronger relationship between $\log$ (density) and clade-specific species richness

273 within closely-related groups such as the Psittaciformes, Trochilidae, Tyranni, and Passeri

274 compared to the diffuse non-Passeriformes, which includes birds from tinamous to vultures.

275 Each group was analyzed using a separate model that included lower-level taxa as random

276 effects, and the significance of group-specific richness was assessed using the likelihood ratio

277 test.

278 The sequential regressions that we used were nested within one another, such that the simpler

279 models were subsets of more complex ones. This was advantageous because it allowed us to see

280 whether adding each new variable that corresponded to an additional hypothesis made a

281 significant improvement in model fit by using both the likelihood ratio test (LRT) and the

282 Akaike Information Criterion (AIC; Akaike 1974, Burnham and Anderson 2004, Bolker 2008).

283 Furthermore, the most complex model makes it possible to assess at a glance the relative

284 contributions of each predictor to explaining the variance.

285 A caveat in interpreting sequential regression is that it is sensitive to the order in which

286 orthogonal axes are created. We chose the sequence of regressions to accord with our a priori

287 hypotheses for how variables influence one another. However, we wished to examine the

288 robustness of our results to a different statistical method. To do so, we also performed a linear

289 mixed model with habitat, NPP, and regional species richness as fixed predictors of $\log$ (density), 
Neotropical Bird Abundance

290 and order/family/genus as random effects. This approach does not use orthogonal predictors, but

291 does break free from some of our assumptions.

292

293 Results

294 We found no evidence that survey methods yielded significantly different density estimates

295 (likelihood ratio test $\left.(\mathrm{LRT}) ; \chi_{2}^{2}=0.49 ; \mathrm{p}=0.78\right)$.

296 The linear regression of $\log$ (density) against $\log$ (body mass) was statistically significant

297 (OLS regression, $\mathrm{r}^{2}=0.08, \mathrm{~F}_{1,1063}=93.23, \mathrm{p}<10^{-3}$; Figure $3 \mathrm{~A}$ ). However, its fit to the data was

298 poor compared with a model that had no fixed effects, but included order, family, and genus as

299 random effects (Table 1). This occured because the largest proportion of variance in body size

300 was explained at the levels of genus (0.14), family (0.18) and order (0.65), whereas the variance

301 by species and site (combined in the residuals; 0.03 ) was low. The OLS regression of geometric

302 mean density of families against their geometric mean body mass had a better fit than the

303 regression on the species level (OLS regression, $\mathrm{r}^{2}=0.29, \mathrm{~F}_{1,18}=7.21, \mathrm{p}=0.015$; Figure 3B).

304 Habitat type made a strong contribution to model fit (Table 1 ; LRT: $\chi_{5}^{2}=121.55 ; \mathrm{p}<10^{-3}$ ).

305 Relative to Amazonian forests, Atlantic and coniferous forests were estimated to have lower

306 population densities, while dry, humid, and montane forests were estimated to have higher

307 densities (Table 2).

308 The productivity hypothesis predicts that species abundances are positively correlated with

309 NPP, once the contribution of NPP due to its correlation with habitat structure is taken into

310 account. This prediction was not confirmed (LRT: $\left.\chi_{1}^{2}=1.29 ; \mathrm{p}=0.26\right)$, although the estimated

311 coefficient was in the predicted direction (Table 2). 
Neotropical Bird Abundance

The interspecific competitors hypothesis predicts that population densities will decrease with

313 increasing species richness. We tested this effect after taking into account the contribution that

314 species richness made to $\log$ (density) through its correlation with NPP and habitat. This

315 prediction of the interspecific competitors hypothesis was confirmed (LRT: $\chi_{1}^{2}=33.2 ; \mathrm{p}<10^{-3}$ ).

316 Its effect size was on the same order of magnitude as the largest effect sizes for different habitat

317 levels (Table 2).

318 We used AIC to compare the fit of all of the models that we fit for $\log ($ density). This

319 provided an alternative to the likelihood ratio test to see if there was an improvement in model fit

320 when each predictor was added to the model. We found that the addition of each predictor

321 resulted in an improvement in model fit by at least 2 points, with the exception of productivity

322 (Table 1). The $\triangle \mathrm{AIC}$ separating the best-fit model from others was 30.5, indicating almost no

323 support for any of the simpler models, and therefore arguing that the residuals of species richness

324 are indispensable as a predictor of $\log ($ density).

325 Within taxonomic groups, species richness was an inconsistent predictor of population

326 density. Although in all cases the estimated relationship was negative, in the non-Passeriformes

327 (excluding Psittaciformes and Trochilidae) and the Passeri, species richness of each group was

328 not a significant predictor of population density (Table 3). By contrast, in the Psittaciformes,

329 Trochilidae, and Tyranni, it was (Table 3).

330 Results from a linear mixed model with predictors included simultaneously were largely in

331 agreement with those of sequential regressions (Table 4). In this model, NPP was a significant

332 predictor of population density in the predicted direction (LRT: $\chi_{1}^{2}=16.9 ; \mathrm{p}<10^{-3}$ ), although

333 the magnitude of its effect remained small compared with those of species richness and different 
Neotropical Bird Abundance

334 levels of habitat. Habitat (LRT: $\chi_{1}^{2}=39.5 ; \mathrm{p}<10^{-3}$ ) and species richness (LRT: $\chi_{1}^{2}=33.2 ; \mathrm{p}<$

$33510^{-3}$ ) remained significant predictors of $\log ($ density $)$.

\section{Discussion}

338 To understand causes of variation in population abundance at a continental scale, we took data

339 on densities of Neotropical forest bird species and tested four hypotheses based on body mass,

340 productivity, interspecific competitors, and habitat. We used sequential regression to construct

341 the most likely series of relationships between these explanatory variables. First, we took into

342 account effects of body mass. Then, we postulated that habitat would have an independent

343 influence on abundance, and that within habitats, productivity could modify abundances. Finally,

344 we hypothesized that the richness of competing species should determine the way that species

345 divide up the available productivity within habitats. Using this approach, we found support for

346 the importance of all the explanatory variables except for productivity in predicting abundances.

347 Multiple regression largely agreed with the results of sequential regression, although NPP had a

348 small yet significant effect in the predicted direction.

349 Body mass explains relatively little variance when it is a fixed effect used to model

350 abundance on the species level, but on the family level this variable explains much more

351 variation in abundance. Other authors have also noted this relationship between body size and

352 taxonomic level, and the ability to predict abundance (Hurlbert and White 2007; McGill 2008).

353 Of all of the variables we examined, habitat type appeared to have the greatest effect on the

354 population abundance of birds (Table 2; Table 4). Montane forests have previously been found to

355 host higher avian population densities (Kattan and Beltran 2002, Ding et al. 2005, Kikuchi 2009,

356 Ferenc et al. 2016). Why should species of birds in humid forest, montane forest, and dry forest 
Neotropical Bird Abundance

357 have higher densities than those found in Amazonian, Atlantic, or coniferous forest? One

358 possibility is that available energy is divided among fewer niches in some habitats. A potential

359 mechanism by which this might come about is through a decrease in the ratio of forest

360 height:productivity. Avian niches are often circumscribed by foliage height diversity and volume

361 (Willson 1974). If foliage height diversity changes more rapidly than productivity between two

362 habitats, there may be fewer niches among which productivity is distributed. For example, if two

363 species divide their foraging among canopy and understory in one habitat, but those two layers

364 are combined in another habitat, one species may be competitively excluded by the

365 disappearance of its niche. Additionally, high rates of topsoil turnover in regions prone to

366 landslides and earthquakes could elevate the available nutrients. Another possibility is that

367 density compensation may occur in some bird communities (Ferenc et al. 2016). Although we

368 found an independent effect of species richness on abundance, even after its correlation with

369 habitat had been taken into account (in our combined model), some of the variance in these two

370 predictors was inextricably confounded, potentially reducing the apparent effects of competitive

371 release. Finally, the metapopulation dynamics of lowland forests (i.e. Amazonian and Atlantic

372 forests) and other forests could be different. In the lowlands, groups that fare poorly at some sites

373 may nevertheless be more easily rescued by immigration through the matrix of forest; in other

374 areas such as montane forest, maintenance of low-density populations in areas to which they are

375 poorly adapted may be impossible because of geographical barriers.

376 The interspecific competitors hypothesis is supported. Particularly, the effect of species

377 richness was strongest within the hummingbirds (Table 3), which feed within the same trophic

378 level and display signatures of competition in the distribution of traits among their assemblages

379 (Graham et al. 2012, Maglianesi et al. 2014). Competition may also be fierce in the Tyranni, 
which often specialize in the interiors of forests (Ricklefs 2002). Studies that have found correlations between density, species richness, and mean territory size have to a large degree focused on this group, in the forest interior (Kikuchi 2009). The negative relationship between density and species richness in the Psittaciformes also accords with the predictions of the

384 interspecific competitors hypothesis, although we do not have a particular explanation as to why

385 besides their shared evolutionary history. The Passeri may suffer less from competition than

386 other monophyletic groups, having recently invaded South America where they typically inhabit

387 the canopy and feed on a greater diversity of carbohydrate foods (Ricklefs 2002),. Finally, the

388 lack of a relationship between density and species richness in non-Passerines (excluding

389 Psittaciformes and Trochilidae) is wholly in agreement with the predictions of the interspecific

390 competitors hypothesis, as this group is paraphyletic, with miscellaneous trophic ecologies,

391 microhabitat preferences, and life history strategies.

392 Competition may be a pervasive force in determining bird species abundance across the

393 Neotropics. Some continental localities may have lower equilibrium species richness than others

394 of equivalent productivity if they are more difficult to colonize, or subject to more frequent local

395 extinction (sensu Hanski 1982). This may be the case in montane communities because of area

396 effects along elevational belts (Kattan and Franco 2004), or environmental filtering (e. g.,

397 temperature or precipitation effects; Graham et al. 2012). If depauperate communities exhibit

398 density compensation, then they may host avifauna occupying larger realized niches than those

399 in lowland forests; it would be fascinating to know if this is the case, and whether individuals

400 have broader niches, or populations are composed of more variable individuals (Van Valen 1965,

$401 \quad$ Bolnick et al. 2015). 
Neotropical Bird Abundance

402

403

404

405

406

407

408

409

410

411

412

413

414

415

416

417

Productivity itself was a poor predictor of species abundance, explaining negligible variance (Table 1), although whether or not it was a significant predictor depended on the statistical method used (Table 2 vs. Table 4). This result is perhaps unsurprising, as productivity has the most scope to explain total abundance of all individuals summed across species, and moreover between large (e.g. continental) regions (Storch et al. 2018). Willson (1974) and Hurlbert (2004) also found that productivity was a poor predictor of the abundance of forest birds. Hurlbert (2004) suspected a bias in the Breeding Bird Survey data that he used. Any such bias in our study would be far less, however, due to the exhaustive methods of many studies that we included in our database (hours of sampling effort for each transect of the BBS, versus months of for the plots in the studies used here).

After using either sequential or multiple regression, much unexplained variance remains. This variance may be attributed to other variables that we did not include in this study, but which are correlated with the ones that we used; however, a priori hypothesis testing through sequential regression is the best precaution we could take against this possibility, balancing thoroughness against the inevitable improvement in model fit that more predictors bring. Specific traits that are less phylogenetically conserved than body mass may improve estimates of species abundance. Traits that reflect ecological specialization such as foraging substrate and method, circadian and seasonal activity patterns, and aspects of morphology related to foraging and movement may be worthwhile avenues of investigation (Pigot et al. 2016). The data structure required to explain how traits influence species abundance may be complex, however (Warton et al. 2015). Furthermore, better validation of methods used to measure avian densities in tropical habitats may reduce noise in estimates. 
Neotropical Bird Abundance

424

425

426

427

428

429

430

431

432

433

434

435

436

437

438

439

440

441

442

443

444

445

446

It is possible to count on one hand the number of studies that have completely described the abundance of breeding birds in Neotropical avian communities (Terborgh et al. 1990, Thiollay 1994, Robinson et al. 2000, Johnson et al. 2011). All are from lowland rainforest. Other studies in other habitats have described subsets of communities, often delimited by functional guilds (Kattan and Beltran 2002, Stouffer 2007, Kikuchi 2009). The data coverage of some areas, especially Atlantic forest, Andean forests south of Ecuador, and many drier biomes such as Cerrado, Chaco, and Caatinga, is exceptionally sparse. Given that many fundamental questions in ecology and evolution require being able to calculate abundances and biomass, the importance of gathering abundance data from complete avian communities in a variety of Neotropical habitats cannot be overstated. Future work on the community structure should measure both population densities and species richness, particularly at multiple sites across ecological gradients.

The pith of our study reveals that hypotheses that attempt to connect the abundance of species to energy, whether via body mass (as energy consumption) or via productivity (as energy availability), fall short unless certain caveats are observed. In the case of body mass, the caveat is statistical: population density is better explained at higher taxonomic levels. In the case of productivity, perhaps its effect on abundances depends on the way available energy is partitioned according to habitat structure. Ecologically oriented hypotheses such as the type of forest habitat and the number of potential competitors are better predictors of species abundances. However, ultimately habitat type and the number of competitors reflect patterns of energy distribution among consumers in complex environments, so for predictive purposes these two variables may be more important, but mechanistically the abundance structure of communities is probably dependent on energy fluxes (McGill et al. 2007). 
Neotropical Bird Abundance

\section{Acknowledgments}

449 We thank Allen Hurlbert and two anonymous reviewers for helpful comments.

$451 \quad$ Funding

452 DWK was supported by NIH-2K12GM000708-18.

\section{Data}

455 All data used in the analyses performed in this study are available as online supplements

\section{$457 \quad$ References}

458 Akaike, H. 1974. A new look at the statistical model identification. - IEEE Trans. Automat. Contr. 19: 716-723.

460 Berger, K. M. and Gese, E. M. 2007. Does interference competition with wolves limit the 461 distribution and abundance of coyotes? - J. Anim. Ecol. 76: 1075-1085.

462 Bolker, B. M. 2008. Ecological Models and Data in R. - Princeton University Press.

463 Bolnick, D. I. et al. 2015. The ecology of individuals: incidence and implications of individual 464 specialization. - Am. Nat. 161: 1-28.

465 Brown, J. H. 1995. Macroecology. - University of California Press.

466 Brown, J. H. and Maurer, B. A. 1987. Evolution of species assemblages: effects of energetic 467 constraints and species dynamics on the diversification of the North American avifauna. $468 \quad$ Am. Nat. 130: 1-17.

469 Brown, J. H. et al. 2004. Toward a metabolic theory of ecology. - Ecology 85: 1771-1789. 
Neotropical Bird Abundance

470

471

472

473

474

475

476

477

478

479

480

481

482

483

484

485

486

487

488

489

490

491

492

Buckland, S. T. et al. 2015. Distance sampling: methods and applications. - Springer International Publishing.

Burnham, K. P. and Anderson, D. R. 2004. Multimodel Inference. - Sociol. Methods Res. 33: 261-304.

Charlesworth, B. 2009. Fundamental concepts in genetics: effective population size and patterns of molecular evolution and variation. - Nature 10: 195-205.

Connor, E. F. and Simberloff, D. 1979. The assembly of species communities: chance or competition? - Ecology 60: 1132-1140.

Crowell, K. L. 1962. Reduced interspecific competition among the birds of Bermuda. - Ecology 43: 75-88.

Damuth, J. 1981. Population density and body size in mammals. - Nature 290: 699-700.

del Hoyo, J. et al. 2016. Handbook of birds of the world alive. - Lynx Ediciones.

Diamond, J. M. and Gilpin, M. E. 1982. Examination of the "null" model of Connor and Simberloff for species co-occurrences on islands. - Ecology 52: 64-74.

Ding, T. S. et al. 2005. Energy flux, body size and density in relation to bird species richness along an elevational gradient in Taiwan. - Glob. Ecol. Biogeogr. 14: 299-306.

Dormann, C. F. et al. 2013. Collinearity : a review of methods to deal with it and a simulation study evaluating their performance. - Ecography 36: 27-46.

Ferenc, M. et al. 2016. Abundance-area relationships in bird assemblages along an Afrotropical elevational gradient: space limitation in montane forest selects for higher population densities. - Oecologia 181: 225-233.

Freckleton, R. P. 2002. On the misuse of residuals in ecology: regression of residuals vs . multiple regression. - J. Anim. Ecol. 71: 542-545. 
Neotropical Bird Abundance

493 Gotelli, N. J. 1995. A primer of ecology. - Sinauer Associates Incorporated.

494 Gotelli, N. J. and McCabe, D. J. 2002. Species co-occurrence: A meta-analysis of J. M.

495 Diamond's assembly rules model. - Ecology 83: 2091-2096.

496 Graham, M. H. 2003. Confronting multicollinearity in ecological multiple regression. - Ecology 497 84: 2809-2815.

498 Graham, C. H. et al. 2012. Untangling the influence of ecological and evolutionary factors on 499 trait variation across hummingbird assemblages. - Ecology 93: 99-111.

500 Hanski, I. 1982. Dynamics of regional distribution: the core and satellite species hypothesis. $501 \quad$ Oikos 38: 210-221.

502 Harmon, L. J. and Harrison, S. 2015. Species diversity is dynamic and unbounded at local and 503 continental scales. - Am. Nat. 185: 584-593.

504 Hudson, P. J. et al. 1992. Do parasites make prey vulnerable to predation? Red Grouse and 505 parasites. - J. Anim. Ecol. 61: 681-692.

506 Hurlbert, A. H. 2004. Species - energy relationships and habitat complexity in bird communities. $507 \quad$ - Ecol. Lett. 7: 714-720.

508 Hurlbert, A. H. and White, E. P. 2007. Ecological correlates of geographical range occupancy in $509 \quad$ North American birds. - Glob. Ecol. Biogeogr. 16: 764-773.

510 Hutchinson, G. E. 1957. Concluding Remarks. - Cold Spring Harb. Symp. Quant. Biol. 22: 415$511 \quad 427$.

512 Jankowski, J. E. et al. 2012. The role of competition in structuring tropical bird communities. 513 Ornitol. Neotrop. 23: 115-124.

514 Jenkins, C. N. et al. 2013. Global patterns of terrestrial vertebrate diversity and conservation. 515 Proc. Natl. Acad. Sci. 110: E2602-10. 
Neotropical Bird Abundance

516

517

Johnson, E. I. et al. 2011. Diversity, biomass and trophic structure of a central Amazonian rainforest bird community. - Rev. Bras. Ornitol. 19: 1-16.

Kaspari, M. et al. 2000. Energy, density, and constraints to species richness: ant assemblages along a productivity gradient. - Am. Nat. 155: 280-293.

Kattan, G. H. and Beltran, J. W. 2002. Rarity in antpittas: territory size and population density of five Grallaria spp. in a regenerating habitat mosaic in the Andes of Colombia. - Bird Conserv. Int. 12: 231-240.

Kattan, G. H. and Franco, P. 2004. Bird diversity along elevational gradients in the Andes of Colombia: area and mass effects. - Glob. Ecol. Biogeogr. 13: 451-458.

Kattan, G. H. et al. 2016. Population densities of curassows, guans, and chachalacas (Cracidae): effects of body size, habitat, season, and hunting. - Condor Ornithol. Appl. 118: 24-32.

Kikuchi, D. W. 2009. Terrestrial and understorey insectivorous birds of a Peruvian cloud forest: species richness, abundance, density, territory size and biomass. - J. Trop. Ecol. 25: 523529.

Losos, J. B. 2008. Phylogenetic niche conservatism, phylogenetic signal and the relationship between phylogenetic relatedness and ecological similarity among species. - Ecol. Lett. 11: $995-1003$.

MacArthur, R. H. 1957. On the relative abundance of bird species. - Proc. Natl. Acad. Sci.: 293295.

MacArthur, R. H. et al. 1972. Density compensation in island faunas. - Ecology 53: 330-342.

Maglianesi, M. A. et al. 2014. Morphological traits determine specialization and resource use in plant-hummingbird networks in the neotropics. - Ecology 95: 3325-3334.

McGill, B. J. 2008. Exploring predictions of abundance from body mass using hierarchical 
Neotropical Bird Abundance

comparative approaches. - Am. Nat. 172: 88-101.

540

McGill, B. J. et al. 2006. Rebuilding community ecology from functional traits. - Trends Ecol. Evol. 21: 178-185.

McGill, B. J. et al. 2007. Species abundance distributions: moving beyond single prediction theories to integration within an ecological framework. - Ecol. Lett. 10: 995-1015.

Murcia, C. 1995. Edge effects in fragmented forests: implications for conservation. - Trends Ecol. Evol. 10: 58-62.

Murray, B. R. et al. 2002. How plant life-history and ecological traits relate to species rarity and commonness at varying spatial scales. - Austral Ecol. 27: 291-310.

Nilsson, S. G. 1977. Density compensation and competition among birds breeding on small islands in a south Swedish lake. - Oikos 28: 170-176.

Pigot, A. L. et al. 2016. Functional traits reveal the expansion and packing of ecological niche space underlying an elevational diversity gradient in passerine birds. - Proc. R. Soc. B 283: 20152013.

Pimm, S. L. et al. 2014. The biodiversity of species and their rates of extinction, distribution, and protection. - Science 344: 1246752.

Rabosky, D. L. and Hurlbert, A. H. 2015. Species richness at continental scales is dominated by ecological limits. - Am. Nat. 185: 572-583.

Ricklefs, R. E. 2002. Splendid isolation: historical ecology of the South American passerine avifauna. - J. Avian Biol. 33: 207-211.

Robertson, D. R. 1996. Interspecific competition controls abundance and habitat use of territorial caribbean damselfishes. - Ecology 77: 885-899.

Robinson, W. D. et al. 2000. Forest bird community structure in central Panama: influence of 
Neotropical Bird Abundance

562

563

564

565

566

spatial scale and biogeography. - Ecol. Monogr. 70: 209-235.

Rosenzweig, M. L. and Lomolino, M. V 1997. Who gets the short bits of the broken stick? - In: Kunin, W. E. and Gaston, K. J. (eds), The biology of rarity: causes and consequences of rare-common differences. Chapman and Hall, pp. 63-86.

Russo, S. E. et al. 2003. Size-abundance relationships in an Amazonian bird community: implications for the energetic equivalence rule. - Am. Nat. 161: 267-283.

Schulenberg, T. S. 2016. Neotropical birds online. - Cornell Lab of Ornithology.

Srivastava, D. S. and Lawton, J. H. 1998. Why more productive sites have more species: an experimental test of theory using tree $\square$ hole communities. - Am. Nat. 152: 510-529.

Storch, D. et al. 2018. The more-individuals hypothesis revisited: the role of community abundance in species richness regulation and the productivity-diversity relationship. - Ecol. Lett. 21: 920-937.

Stouffer, P. C. 2007. Density, territory size, and long-term spatial dynamics of a guild of terrestrial insectivorous birds near Manaus, Brazil. - Auk 124: 291-306.

Terborgh, J. et al. 1990. Structure and organization of an Amazonian forest bird community. Ecol. Monogr. 60: 213-238.

Thiollay, J. 1994. Structure, density and rarity in an Amazonian rainforest bird community. - J. Trop. Ecol. 10: 449-481.

Ulrich, W. and Gotelli, N. J. 2010. Null model analysis of species associations using abundance data. - Ecology 91: 3384-3397.

Umaña, M. N. et al. 2015. Commonness, rarity, and intraspecific variation in traits and performance in tropical tree seedlings. - Ecol. Lett. 18: 1329-1337.

Van Valen, L. 1965. Morphological variation and width of ecological niche. - Am. Nat. 99: 377- 
Neotropical Bird Abundance 390.

586 Warton, D. I. et al. 2015. So many variables: joint modeling in community ecology. - Trends $587 \quad$ Ecol. Evol. 30: 766-779.

588 White, E. P. and Hurlbert, A. H. 2010. The combined influence of the local environment and 589 regional enrichment on bird species richness. - Am. Nat. 175: E35-E43.

590 White, E. P. et al. 2007. Relationships between body size and abundance in ecology. - Trends $591 \quad$ Ecol. Evol. 22: 323-330.

592 Willson, M. F. 1974. Avian community organization and habitat structure. - Ecology 55: 1017$593 \quad 1029$.

594 Wright, S. J. 1980. Density compensation in island avifaunas. - Oecologia 45: 385-389.

595 Zhao, M. et al. 2005. Improvements of the MODIS terrestrial gross and net primary production 596 global data set. - Remote Sens. Environ. 95: 164-176. 
598 Table 1. Factors affecting population densities of Neotropical forest birds. The table shows all of 599 the species-level models of $\log$ (density) fitted in the study, with their number of parameters $k$, 600 AIC scores, and $\triangle \mathrm{AIC}$ scores separating them from the best-fit model.

601

\begin{tabular}{lllll}
\hline Fixed effects & Random effects & $k$ & AIC & $\Delta$ AIC \\
\hline$\sim$ habitat + resid(NPP $\sim$ habitat $)+$ & order/family/genus & 12 & 3474 & 0 \\
resid(species richness $\sim$ resid(NPP $\sim$ habitat) $)$ & & & \\
$\sim$ habitat + NPP + species richness & order/family/genus & 12 & 3474 & 0 \\
$\sim$ habitat & order/family/genus & 11 & 3504 & 30.5 \\
$\sim$ habitat + resid(NPP $\sim$ habitat $)$ & order/family/genus & 10 & 3505 & 31.2 \\
$\sim 1$ & order/family/genus & 5 & 3615 & 142 \\
$\sim \log ($ body mass $)$ & none & 3 & 3653 & 180
\end{tabular}

602

603

604

605

606

607

608

609

610

611 


\section{Neotropical Bird Abundance}

612 Table 2. Summary of results of the most complex sequential regression model explaining

613 population density of Neotropical forest birds as a function of habitat type, net primary

614 productivity and species richness. Forest habitat (factor) and the residuals of NPP (continuous)

615 and residuals of species richness (continuous) were predictors.

616

\begin{tabular}{lll}
\hline Effect & Estimate & Std. error \\
\hline Amazonian Forest (reference) & 1.41 & 0.15 \\
Atlantic Forest & -0.65 & 0.62 \\
Coniferous Forest & -0.49 & 0.24 \\
Dry Forest & 0.21 & 0.50 \\
Humid Forest & 0.22 & 0.09 \\
Mountain Forest & 0.24 & 0.25 \\
resid(NPP habitat) & 0.04 & 0.04 \\
resid(species richness & & \\
resid (NPP habitat) & -0.56 & 0.10 \\
\hline
\end{tabular}


Neotropical Bird Abundance

620 Table 3. The effects of the species richness of groups on the population densities of their

621 members, including the significance of resid(species richness $\sim$ resid(NPP $\sim$ habitat type) as

622 assessed by the likelihood ratio test, and estimated effect sizes and standard errors.

623

\begin{tabular}{lcccc}
\hline Group & $\chi_{1}^{2}(\mathrm{LRT})$ & $\mathrm{p}$-value & Effect size & Standard error \\
\hline non-Passeriformes (excluding & 0.29 & 0.59 & -0.09 & 0.16 \\
Psittaciformes and Trochilidae) & & & & \\
Psittaciformes & 12.47 & $<10^{-3}$ & -0.75 & 0.20 \\
Trochilidae & 14.58 & $<10^{-3}$ & -1.34 & 0.31 \\
Tyranni (suboscines) & 20.2 & $<10^{-3}$ & -0.61 & 0.13 \\
Passeri (oscines) & 0.82 & 0.36 & -0.08 & 0.09 \\
& & & & \\
\hline
\end{tabular}

624 


\section{Neotropical Bird Abundance}

625 Table 4. Summary of results of the linear mixed model where predictors were fit simultaneously,

626 for comparison with the sequential regressions. Forest habitat (factor), NPP (continuous), and

627 species richness (continuous) were predictors.

628

\begin{tabular}{lcc}
\hline Effect & Estimate & Std. error \\
\hline Amazonian Forest (reference) & 1.48 & 0.16 \\
Atlantic Forest & -0.66 & 0.62 \\
Coniferous Forest & -0.36 & 0.23 \\
Dry Forest & 0.33 & 0.50 \\
Humid Forest & 0.42 & 0.09 \\
Mountain Forest & 0.46 & 0.23 \\
NPP & 0.19 & 0.05 \\
Species Richness & -0.56 & 0.09 \\
\hline
\end{tabular}

630

631

632 
Neotropical Bird Abundance

633

634

635 Figure 1. Locations of study sites (black dots) in final dataset of population density estimates of

636 Neotropical forest birds, superimposed on an elevational map of the Neotropics ( $\mathrm{m}$ asl = meters

637 above sea level). Radius of dots is related to $\log _{2}$ (number of species sampled at each site):

638 minimum records $=1 ;$ maximum records $=230$.

640 Figure 2. Metadata describing the final dataset, with median measures used for multiple

641 observations of the same species at the same site. A. Distribution of NPP values among records.

642 B. Distribution of records per species. Most Neotropical species are represented by only a single

643 density observation. C. Plot representing the number of records by habitat type and survey

644 method used. The size of the colored rectangles is proportional to the number of records. D.

645 Distribution of records from individual studies. Four major studies in lowland rainforest

646 contributed a large number of records.

647

648 Figure 3. A) Population densities of Neotropical forest bird species regressed against body mass

649 on a log-log scale. B) Geometric mean population densities of Neotropical forest bird families

650 regressed against $\log$ (geometric mean body mass) on a log-log scale. 


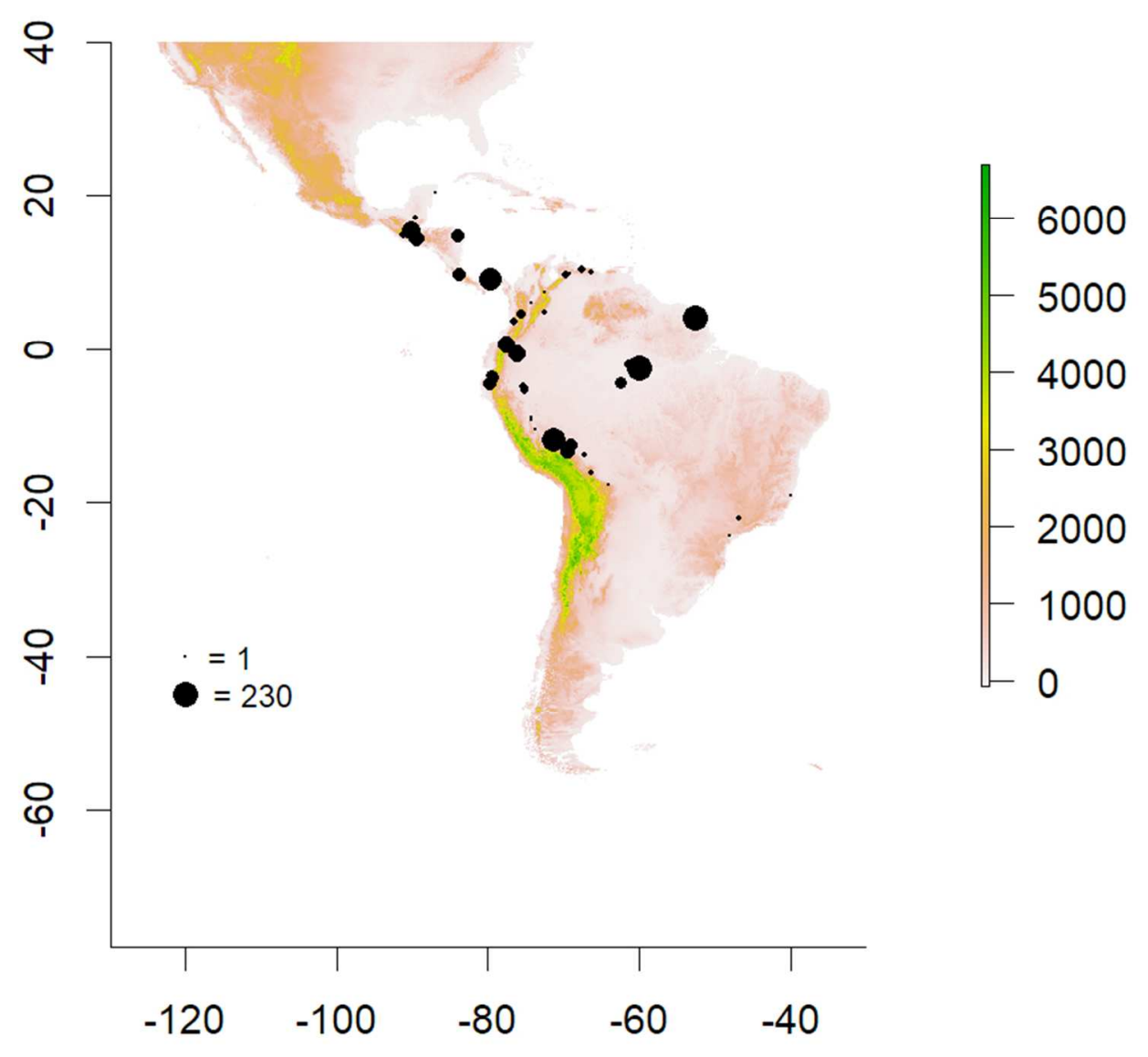



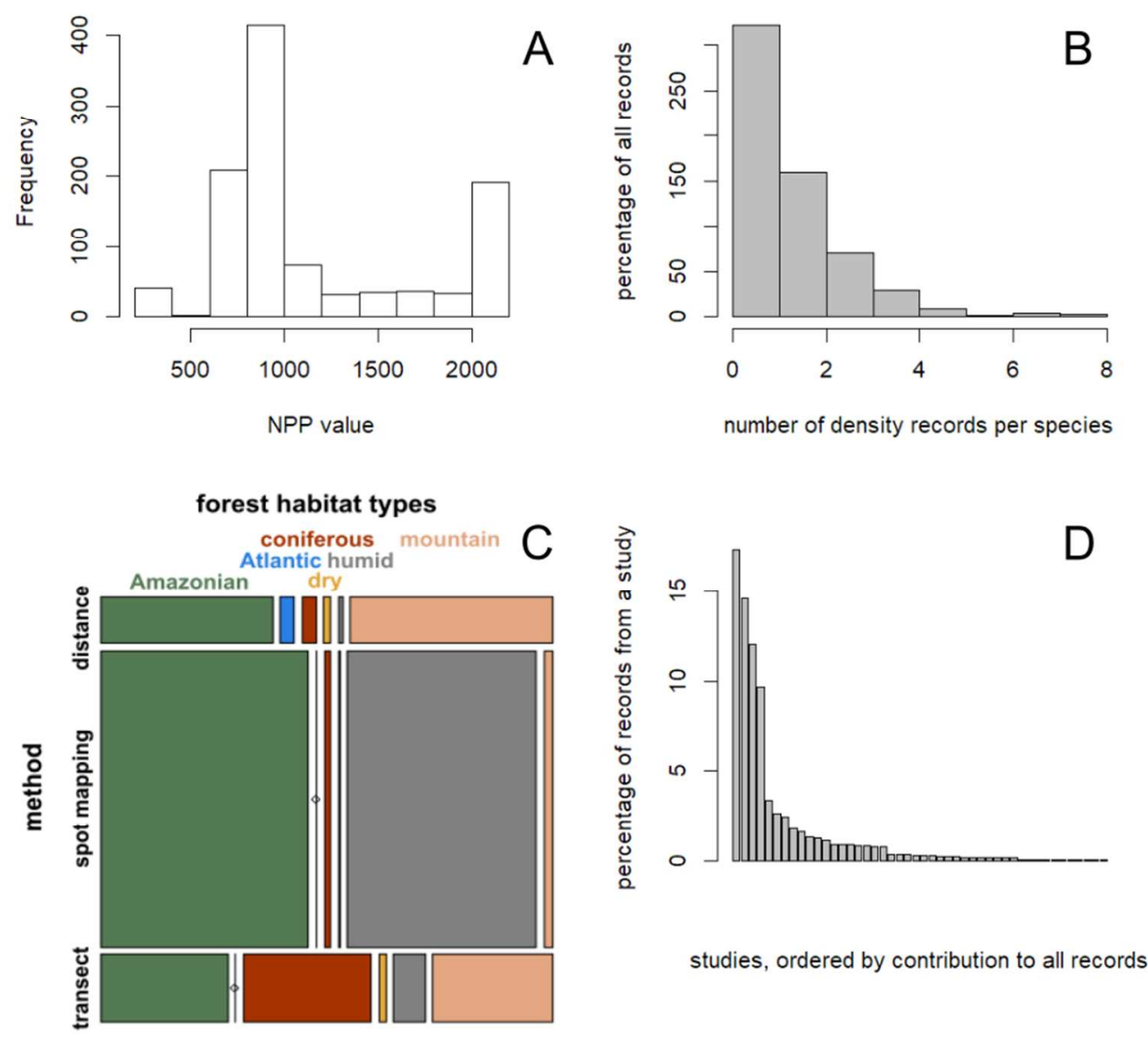

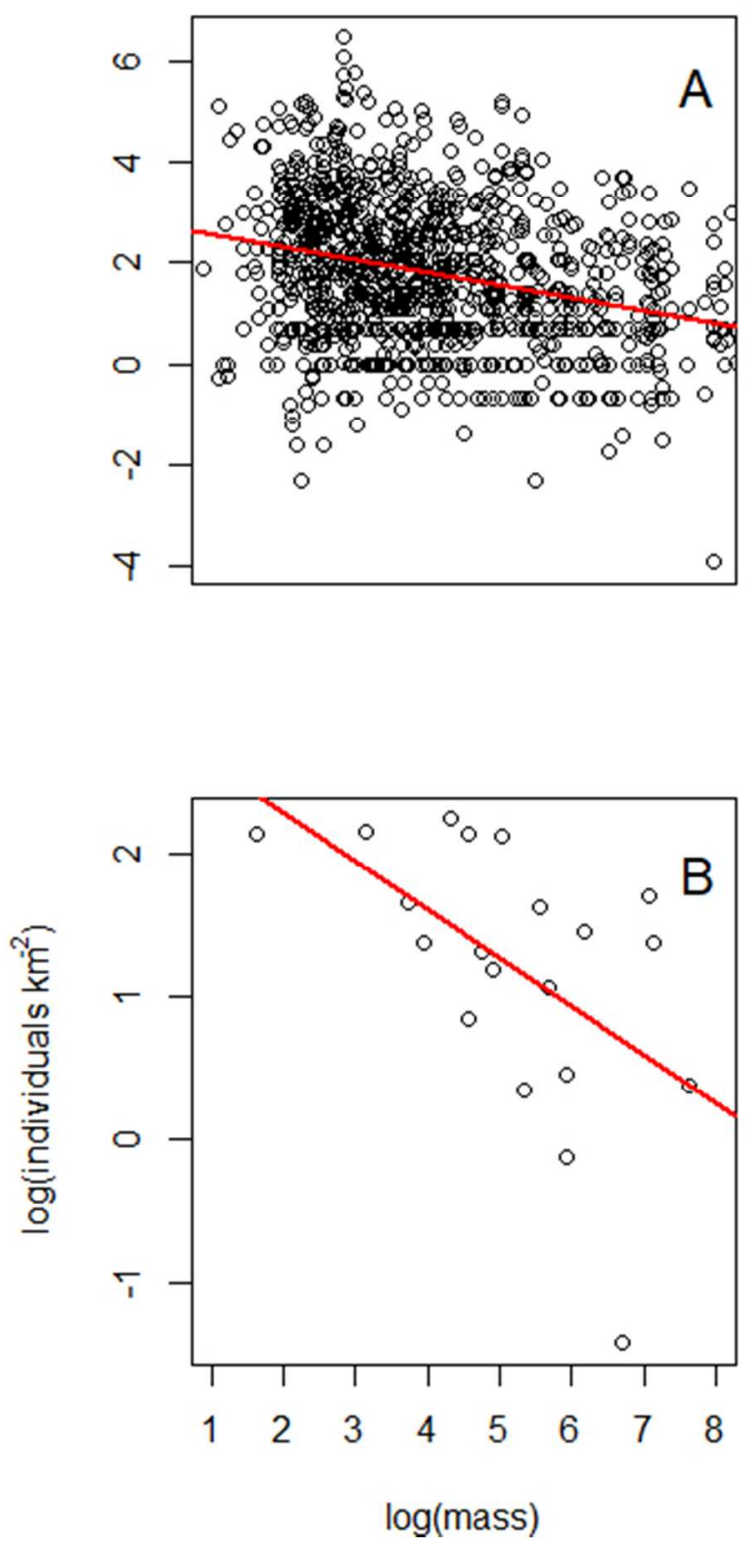
Key to fields in DataA1.csv: id = an arbitrary record identification number; ords = order; family = family; genus = genus; $\mathrm{sp}=$ species Latin binomial; mig = migration status; study = citation from which data were retrieved (see list below); meth = survey method; lat = decimal degrees latitude; long = decimal degrees longitude; $y=$ population density (individuals $\mathrm{km}^{-2}$ ); elev = elevation (masl); npp = net primary productivity, centered and scaled; nonPass = species richness of non-Passeriformes, centered and scaled; Psittaciformes $=$ species richness of Psittaciformes, centered and scaled; Trochilidae $=$ species richness of Trochilidae, centered and scaled; Tyranni = species richness of Tyranni, centered and scaled; Passeri $=$ species richness of Passeri, centered and scaled; all = regional species richness (all birds), centered and scaled; mass = body mass of the species $(\mathrm{g})$; habitat $=$ habitat type; guild $=$ speculation as to foraging guild (not used in analysis).

\section{List of References Included in Data S1}

Alves, F., G. M. López-Iborra, and L. F. Silveira. 2015. Population size assessment of the endangered Red-billed Curassow Crax blumenbachii: accounting for variation in detectability and sex-biased estimates. Oryx:1-9.

Barrio, J. 2011. Hunting pressure on cracids (Cracidae: Aves) in forest concessions in Peru. Revista Peruana de Biologia 18:225-230.

Begazo, A. J., and R. E. Bodmer. 1998. Use and conservation of Cracidae (Aves: Galliformes) in the Peruvian Amazon. Oryx 32:301-309.

Blake, J. G. 2007. Neotropical forest bird communities: a comparison of species richness and composition at local and regional scales. The Condor 109:237-255.

Borges, S. H., L. M. Henriques, and A. Carvalhaes. 2004. Density and habitat use by owls in two Amazonian forest types. Journal of Field Ornithology 75:176-182.

Cleary, K. A. 2010. Species richness, densities, habitat relationships, and conservation of the avian community of the highaltitude forests of Totonicapán, Guatemala. Colorado State University.

Cox, G., J. M. Read, R. O. S. Clarke, and V. S. Easty. 1997. Studies of Horned Curassow Pauxi unicornis in Bolivia. Bird Conservation International 7:199-211.

Cresswell, W., M. Hughes, R. Mellanby, S. Bright, P. Catry, J. Chaves, J. Freile, A. Gabela, H. Martineau, R. Macleod, F. Mcphie, N. Anderson, S. Holt, S. Barabas, C. Chapel, and T. Sanchez. 1999. Densities and habitat preferences of Andean cloudforest birds in pristine and degraded habitats in north-eastern Ecuador. Bird Conservation International 9:129-145.

Eisermann, K., C. Avendaño, and P. Tanimoto. 2013. Birds of the Cerro El Amay important bird area, Quiché , Guatemala. Cotinga 35:81-93.

Fierro-Calderón, K., C. Montealegre, E. Fierro-C, and D. Eusse. 2009. Five threatened species at western andes of colombia. Cali, Colombia. 
Galetti, M., P. Martuscelli, F. Olmos, and A. Aleixo. 1997. Ecology and conservation of the Jacutinga Pipile jacutinga in the Atlantic forest of Brazil. Biological Conservation 82:31-39.

Greenberg, R., and J. Gradwohl. 1986. Constant density and stable territoriality in some tropical insectivorous birds. Oecologia 69:618-625.

Guix, J. C. 1997. Exclusao geográfica e ecológica de Penelope obscura, Penelope superciliaris e Pipile jacutinga (Galliformes, Cracidae) no estado de São Paulo. Ararajuba 5:195-202.

Haugaasen, T., and C. A. Peres. 2008. Population abundance and biomass of large-bodied birds in Amazonian flooded and unflooded forests. Bird Conservation International 18:87-101.

Herzog, S. K., A. B. Henessey, M. Kessler, and V. H. García-Solíz. 2008. Distribution, natural history and conservation status of two endemics of the Bolivian Yungas, Bolivian Recurvebill Simoxenops striatus and Yungas Antwren Myrmotherula grisea. Bird Conservation International 18:331-348.

Hill, D. L., H. Arañibar-rojas, and R. Macleod. 2008. Wattled Curassows in Bolivia: abundance, habitat use , and conservation status. Journal of Field Ornithology 79:345351.

Howell, T. R. 1971. Un estudio ecológico de las aves de la sabana de pino de tierras bajas y bosque lluvioso adyacente en el noreste de Nicaragua. Pages 185-242in O. S. Pettingill and D. A. Lancaster, editors. The living bird, Tenth annual. The Laboratory of Ornithology at Cornell University.

Jacobs, M. D., and J. S. Walker. 1999. Density estimates of birds inhabiting fragments of cloud forest in southern Ecuador. Bird Conservation International 9:73-79.

Johnson, E. I., P. C. Stouffer, and C. F. Vargas. 2011. Diversity, biomass, and trophic structure of a central Amazonian rainforest bird community. Revista Brasileira de Ornitologia - Brazilian Journal of Ornithology 19:1-16.

Kattan, G., and W. J. Beltrán. 2002. Rarity in antpittas: territory size and population density of five Grallaria spp . in a regenerating habitat mosaic in the Andes of Colombia. Bird Conservation International 12:231-240.

Kattan, G. H., A. León, G. Corredor, W. Beltrán, and M. Parada. 2006. Distribution and population density of the endangered Cauca Guan Penelope perspicax. Bird Conservation International 16:299-307.

Kattan, G. H., N. Roncancio, Y. Banguera, M. Kessler-rios, G. a Londoño, O. Humberto, and M. C. Muñoz. 2014. Spatial variation in population density of an endemic and endangered bird, the Cauca Guan (Penelope perspicax). Tropical Conservation Science 7:161-170.

Kikuchi, D. W. 2009. Terrestrial and understorey insectivorous birds of a Peruvian cloud forest: species richness, abundance, density, territory size and biomass. Journal of Tropical Ecology 25:523-529. 
Komar, O. 2002. Birds of Montecristo National Park, El Salvador. Ornitologia Neotropical 13:167-193.

Kratter, A. W. 1995. Status, habitat and conservation of the Rufous-fronted Antthrush Formicarius rufifrons. Bird Conservation International 5:391-404.

Kratter, A. W. 1997. Bamboo specialization by Amazonian birds. Biotropica 29:100-110.

Lloyd, H. 2000. Population densities of the Black-faced Cotinga Conioptilon mcilhennyi in south-east Peru. Bird Conservation International 10:277-285.

Lloyd, H. 2003. Population densities of some nocturnal raptor species (Strigidae) in southeastern Peru. Journal of Field Ornithology 74:376-380.

Lloyd, H. 2004. Habitat and population estimates of some threatened lowland forest bird species in Tambopata, south-east Peru. Bird Conservation International 14:261-277.

Martínez-Morales, M. A. 1999. Conservation status and habitat preferences of the Cozumel Curassow. The Condor 101:14-20.

Martínez-Morales, M. A., P. C. Cruz, and A. D. Cuarón. 2009. Predicted population trends for Cozumel Curassows (Crax rubra griscomi): empirical evidence and predictive models in the face of climate change. Journal of Field Ornithology 80:317-327.

Nadachowski, E. 1994. Observaciones sobre la ecología de cuatro especies de paujiles (Cracidae) en el Parque Regional Natural Ucumarí. Pages 329-339in J. O. Rangel, editor.Ucumarí: un caso típico de la diversidad biótica andina. Pereira.

Oostra, V., L. G. L. Gomes, and V. Nijman. 2008. Implications of deforestation for the abundance of restricted-range bird species in a Costa Rican cloud-forest. Bird Conservation International 18:11-19.

Quevedo, A., L. E. Urueña, E. M. Machado, H. D. Arias, E. J. Medina, Z. del P. Castañeda, M. C. Moreno, E. L. Rodríguez, D. M. Cabarcas, P. Laza, I. Melo, H. D. Alvarado, J. M. Ochoa, P. Salaman, T. Donegan, J. Avendaño, and J. D. González. 2008. Proyecto salvando al paujil piquiazul. Conservación Colombiana 4:7-15.

Renner, S. C., M. Waltert, and M. Mühlenberg. 2006. Comparison of bird communities in primary vs. young secondary tropical montane cloud forest in Guatemala. Biodiversity and Conservation 15:1545-1575.

Ríos, M. M., G. A. Londoño, and M. C. Muñóz. 2005. Densidad poblacional e historia natural de la Pava Negra (Aburria aburri) en los Andes centrales de Colombia. Ornitologia Neotropical 16:205-217.

Robinson, W. D., J. D. Brawn, and S. K. Robinson. 2000. Forest bird community structure in central Panama: influence of spatial scale and biogeography. Ecological Monographs 70:209-235.

Schmitz-Ornés, A. 1999. Vulnerability of rufous-vented chachalacas (Ortalis ruficauda, Cracidae) to man-induced habitat alterations in northern Venezuela. Ornitologia Tropical 10:27-34. 
Setina, V., D. J. Lizcano, D. M. Brooks, and L. F. Silveira. 2012. Population density of the Helmeted Curassow (Pauxi pauxi) in Tamá National Park, Colombia. The Wilson Journal of Ornithology 124:316-320.

Silva, J. ., and S. D. Strahl. 1997. Presión de caza sobre las poblaciones de crácidos en los parques nacionales al norte de Venezuela. Pages 437-448in S. . Strahl, S. Beaujon, D. M. Brooks, A. J. Begazo, G. Sedaghatkish, and F. Olmos, editors.The Cracidae: their biology and conservation. Hancock House Publishers, Blaine, Washington.

Stouffer, P. C. 1997. Interspecific aggression in formicarius antthrushes? The view from central Amazonian Brazil. The Auk 114:780-785.

Stouffer, P. C. 2007. Density, territory size, and long-term spatial dynamics of a guild of terrestrial insectivorous birds near Manaus, Brazil. The Auk 124:291-306.

Terborgh, J., S. K. Robinson, T. A. Parker III, C. A. Munn, N. Pierpont, T. A. Parker, C. A. Munn, and N. Pierpont. 1990. Structure and organization of an Amazonian forest bird community. Ecological Monographs 60:213-238.

Thiollay, J.-M. M. 1994. Structure, density and rarity in an Amazonian rainforest bird community. Journal of Tropical Ecology 10:449-481.

Thorstrom, R., P. Nacional, G. De, S. Micrastur, and D. C. M. 2007. Home ranges of Barred (Micrastur Ruficollis) and Collared (M . Semitorquatus) Forest-falcons during the breeding season in Tikal National Park, Guatemala. Ornitologia Neotropical $18: 395-405$.

Torres, B. 1997. Densidades poblacionales de la comunidad de crácidos en el Parque Nacional Manú (Perú). Pages 376-379in S. D. Strahl, S. Beaujon, D. M. Brooks, A. J. Begazo, G. Sedaghatkish, and F. Olmos, editors. The Cracidae: their biology and conservation. Hancock House Publishers, Blaine, Washington.

Willis, E. O. 1974. Population and local extinctions of birds on Barro Colorado Island, Panama. Ecological Monographs 44:153-169. 